\title{
Alphus marinonii sp. nov., nova espécie para o Peru e Brasil (Coleoptera, Cerambycidae, Lamiinae)
}

\author{
Diego de Santana Souza ${ }^{1} \&$ Marcela Laura Monné2,3
}

\begin{abstract}
'Departamento de Zoologia, Universidade Federal do Paraná. Caixa Postal 19020, 81531-980 Curitiba-PR, Brasil. diegosantanasouza@hotmail.com ${ }^{2}$ Museu Nacional, Universidade Federal do Rio de Janeiro, Quinta da Boa Vista, 20940-040 Rio de Janeiro-RJ, Brasil. ${ }^{3}$ Pesquisador do CNPq.
\end{abstract}

\begin{abstract}
Alphus marinonii sp. nov., new species from Peru and Brazil (Coleoptera, Cerambycidae, Lamiinae). A new species of Alphus, A. marinonii sp. nov., from Peru and Brazil (Rondônia) is described. Key to identification and pictures for the four species of the genus are provided. Notes on distribution of A. tuberosus are included, with a new record for Peru and Brazil (Goiás and Mato Grosso do Sul).
\end{abstract}

KEYWORDS. Acanthoderini; key; Neotropical; new record; taxonomy.

O gênero Alphus foi proposto por White (1855) para Lamia tuberosa Germar, 1824. Podemos destacar dois trabalhos em Alphus, o de Martins (1985) e de Restello et al. (2001). Martins (1985) descreveu Alphus similis, relatou a semelhança entre esta espécie, Alphus tuberosus (Germar 1824) e Alphus capixaba Marinoni \& Martins, 1978 e propôs uma chave para identificação deste grupo de espécies. Restello et al. (2001) realocaram as 22 espécies de Alphus em três gêneros, alocaram 13 espécies e descreveram duas em Exalphus e seis espécies em Ateralphus. Em Alphus, concordaram com o grupo de espécies assinalado por Martins (1985): A. capixaba, A. similis Martins, 1985 e A. tuberosus.

Neste trabalho descreve-se uma nova espécie, Alphus marinonii sp. nov. que ocorre no Peru e Brasil, apresentase uma chave para identificação das espécies de Alphus modificada de Martins (1985) e amplia-se a distribuição de A. tuberosus para o Peru e Brasil (Goiás e Mato Grosso do Sul).

O material examinado pertence às seguintes instituições: Museu Nacional, Universidade Federal do Rio de Janeiro (MNRJ), Rio de Janeiro; Museu de Zoologia, Universidade de São Paulo (MZSP), São Paulo. As citações bibliográficas em Alphus tuberosus restringem-se à descrição original e à citação do catálogo de Monné (2005).

\section{Chave para identificação das espécies de Alphus (modificada de Martins (1985))}

1. Lados do pronoto com pubescência branca e densa, situada apenas adiante dos tubérculos e metade posterior evidentemente pontuada; terço apical dos élitros com pubescência branca, sem tufos de cerdas brancas (margem anterior, desta área pubescente, oblíqua em sentido descendente para a sutura e sem prolongamentos de pubescência branca para região anterior dos élitros) (Fig.
1). Brasil (Espírito Santo, Rio de Janeiro)

A. capixaba Marinoni \& Martins

1'. Lados do pronoto com pubescência predominantemente amarelada e densa, à frente e atrás dos tubérculos, na metade posterior com pontos e pubescência esparsa ou inteiramente pubescente; terço apical dos élitros com pubescência branca e ou amarelada, com tufos de cerdas brancas

2(1). Pronoto com região entre os tubérculos medianos, elevada; lados do pronoto com pubescência amarelada e um par de máculas de cerdas brancas, próximas à margem posterior; metade basal dos élitros, junto à sutura, com estreita faixa de cerdas amareladas .............................. 3

2'. Pronoto com região entre os tubérculos medianos não elevada; lados do pronoto com pubescência predominantemente branca, mais amarelada apenas junto à base dos tubérculos aos lados do protórax; élitros, na metade basal, junto à sutura sem faixa estreita de cerdas amareladas (Fig. 2). Brasil (Bahia ao Rio Grande do Sul, Mato Grosso do Sul), Bolívia, Paraguai, Argentina .......A. similis Martins

3(2).Máculas de cerdas brancas na região posterior do pronoto circundada por cerdas castanho-escuras; região mediana dos élitros com dois estreitos ramos de cerdas brancas em direção à crista centro-basal; metade apical dos élitros com diversos tufos irregulares de cerdas brancas (Fig. 3). Brasil (Bahia ao Rio Grande do Sul, Goiás, Mato Grosso do Sul), Peru, Bolívia, Paraguai, Argentina

A. tuberosus (Germar)

3'. Máculas de cerdas brancas na região posterior do pronoto não circundadas por cerdas castanho-escuras; região mediana dos élitros sem faixas de cerdas brancas; terço apical dos élitros com um par de tufos de cerdas brancas (Fig. 4). Peru, Brasil (Rondônia) ............ A. marinonii sp. nov. 



Figs 1-4. 1, Alphus capixaba Marinoni \& Martins, 1978; 2, Alphus similis Martins, 1985; 3, Alphus tuberosus (Germar, 1824); 4, Alphus marinonii sp. nov. (holótipo). Escalas: $1 \mathrm{~mm}$.

Alphus marinonii sp. nov.

(Fig. 4)

Etimologia. Homenagem póstuma ao Prof. Renato C. Marinoni por sua contribuição ao estudo dos Cerambycidae.

Tegumento castanho-avermelhado, mais claro nas antenas; revestido por cerdas predominantemente amareladas.
Cabeça com pontuação fina, densa e pouco aparente, exceto entre os tubérculos anteníferos, grossa e esparsa; com cerdas esbranquiçadas, adensadas nas laterais, atrás dos olhos. Fronte subquadrada; ligeiramente convexa em vista lateral. Lobos oculares inferiores com o dobro da altura da área malar. Genas convergentes. Antenas com cerdas amareladas, com estreito anel de cerdas brancas na base dos artículos II-XI. Escapo 
com cerdas esparsas e amareladas nos $2 / 3$ basais, adensada na região subapical; face interna com cerdas esparsas e longas.

Protórax retangular, com um aguçado tubérculo pós-mediano a cada lado; pronoto com pontuação grossa e irregular; com cerdas esparsas na região dorsal e pubescência amarelada nos lados da metade anterior e mácula de pubescência branca a cada lado do terço posterior. Metade anterior do disco pronotal com dois tubérculos bem projetados, arredondados no ápice e com pontuação fina; área posterior aos tubérculos com linha centro-longitudinal elevada. Processo prosternal deprimido; com margens enegrecidas. Mesosterno com margem anterior deprimida. Processo mesosternal aproximadamente tão largo quanto a mesocoxa; margem posterior bilobada, com uma projeção apical bem pronunciada a cada lado. Mesepisterno com densas cerdas amareladas. Metasterno com um sulco longitudinal no centro, que não atinge a margem anterior; laterais com elevação transversal, com densas cerdas esbranquiçadas. Escutelo subtriangular, com ápice truncado e leve depressão central no terço posterior; pontuação fina; revestido por cerdas amarelas, mais densas nas margens.

Élitros com cristas basais pouco elevadas; pontos grossos, organizados em fileiras longitudinais nos $2 / 3$ basais, entremeados por fileira de cerdas amareladas; sutura com pubescência amarelada; terço apical revestido por cerdas densas castanho-amareladas, a margem anterior branca e com tufo de cerdas brancas. Margem apical dos élitros truncada.

Procoxas com cicatriz longitudinal. Trocanteres com uma cerda castanha, longa. Fêmures com manchas irregulares de pubescência branca e castanha. Tíbias com pubescência branca e esparsa, exceto na metatíbia, com anel branco no ápice. Tarsos com cerdas branco-amareladas.

Abdômen com pontuação fina e irregular. Esternito I tão longo quanto os três seguintes em conjunto; projeção intercoxal aguda, com margem enegrecida levemente sulcada junto às coxas. Último esternito com margem apical arredondada.

Dimensões em mm. Comprimento total, 8,9-9,4; comprimento do protórax, 2,0-2,2; maior largura do protórax, 3,0-3,2; comprimento do élitro, 5,9-6,4; largura umeral, 3,43,6 .

Discussão. Alphus marinonii sp. nov. (Fig. 4) assemelhase a Alphus tuberosus (Fig. 3) e Alphus similis (Fig. 2) pelo padrão da pubescência do corpo. Difere de $A$. tuberosus por não apresentar contorno de cerdas castanhas nas máculas brancas da base do pronoto e pela presença de apenas um tufo de cerdas brancas na área apical pubescente dos élitros. Separa-se de $A$. similis por apresentar elevação entre os tubérculos anteriores do pronoto, um único tufo de pubescência branca no terço apical de cada élitro e pelo escutelo completamente revestido por pilosidade e pelas cristas basais pouco elevadas na base dos élitros.

Material-tipo. Holótipo, PERU, Ucayali: Pucallpa, 7.III.1951, H. Zellibor col. (MNRJ). Parátipos, PERU, Ucayali: Pucallpa, 1 exe., 4.III.1951, 1 exe. 8.III.1951, 27.III.1951, H. Zellibor col. (MNRJ). BRASIL, Rondônia: Costa Marques (Forte Príncipe da Beira), 1 exe. 10.XI.1961, F.M. Oliveira col. (MNRJ).

\section{Alphus tuberosus (Germar, 1824)}

(Fig. 3)

Lamia tuberosa Germar, 1824: 477.

Leiopus tuberosus Germar in Guérin-Méneville, 1839: 329.

Alphus tuberosus; White, 1855: 375; Monné, 2005: 167.

Distribuição geográfica. Ocorre no Brasil (Bahia ao Rio Grande do Sul), Bolívia, Paraguai e Argentina (Monné 2005). Amplia-se a distribuição para o Peru e os estados de Goiás e Mato Grosso do Sul, Brasil.

Material examinado. PERU, Avispas: 1 exe., 10-30.IX.1962, L. Penã col. (MNRJ). BRASIL, Goiás: 1 exe., 15.V (MZSP); Mato Grosso do Sul: Dourados, Itaum, 1 exe., III.1974, Roppa \& Alvarenga col. (MNRJ).

\section{REFERENCIAS}

Germar, E.F. 1824. Insectorum species novae aut minus cognitae, descriptionibus illustratae. Halae, Hendel \& Sons, xxiv+624 p.

Germar, E.F. 1839. In: Guérin-Ménéville, F.E. Note synonymique sur les cérambycins décrits par M. Germar, dans son Insectorum species novae aut minus cognitae, descriptionibus illustratae, Halae, 1824. Revue Zoologique 1839: 329-331.

Marinoni, R.C. \& Martins, U.R. 1978. Notas sinonímicas e novas espécies em Acanthoderini (Coleoptera, Cerambycidae, Lamiinae). Papéis Avulsos de Zoologia 31: 173-193.

Martins, U.R. 1985. Novos táxons, sinonímias, notas e nova combinação em Cerambycidae (Coleoptera) neotropicais. Revista Brasileira de Entomologia 29: 169-180.

Monné, M.A. 2005. Catalogue of the Cerambycidae (Coleoptera) of the Neotropical Region. Part II. Subfamily Lamiinae. Zootaxa 1023: 1-760.

Restello, R.M., Iannuzzi, L. \& Marinoni, R.C. 2001. Descrição de dois novos gêneros afins a Alphus White e duas novas espécies (Cerambycidae, Lamiinae, Acanthoderini). Revista Brasileira de Entomologia 45: 295-303.

White, A. 1855. Catalogue of the coleopterous insects in the collection of the British Museum. part 8, Longicornia 2. London, British Museum, p. 175-412. 